\section{Sigmoidoscopically Induced Pneumatosis Cystoides Coli in Crohn's Disease Manifested by Collar Subcutaneous Emphysema}

A 32-year-old female patient had been treated for colonic inflammatory bowel disease with suspicion of ulcerative colitis for 9 years. As a result of marked weight loss, abdominal pain, and newly developed perineal fistulas, colonoscopy was attempted, but not completed because of an ulcerated, narrowed rectum with significant stenosis at $20 \mathrm{~cm}$. About 3 hours after the uneventful proctosigmoidoscopy, the following clinical signs appeared: collar subcutaneous emphysema, abdominal distension, and pain. Radiographic findings revealed pneumoperitoneum, pneumoretroperitoneum, and pneumomediastinum. An emergency exploration revealed a rigid left colon, strictured ileum characteristic of Crohn's disease, diffuse peritonitis, pneumoretroperitoneum, pneumatosis cystoides of the right colon, and a small area of biliary retroperitoneal imbibition of the hepatic flexure. A total colectomy with Brooke ileostomy and rectal mucuous fistula were made. The macroscopic examination of the specimen revealed a solitary acute ulcer on the otherwise unaffected hepatic flexure (Figure 1). The histological results confirmed Crohn's disease. An elective proctectomy (Figure 2) and extirpation of the fistulas were performed 5 months later. Currently the patient is complaint-free.

Pneumatosis cystoides intestinalis (PCI) is an uncommon and mostly secondary condition of the gastrointestinal tract [1]. Although there are a number of theories to explain the formation of submucosal or subserosal cysts in the bowel wall, mechanical and mucosal damage theories are the most plausible $[2,3]$. In the literature there are reports of cases of endoscopically induced PCI as an iatrogenic complication [4]. In our case, the air insufflation during sigmoidoscopy led to an indirect retroperitoneal perforation of an acute ulcer in the hepatic flexure. This resulted in pneumoretroperitoneum, pneumomediastinum, collar subcutaneous emphysema (the first clinical sign), and PCI of the right colon. The rupture of some of the cysts caused pneumoperitoneum and led to the rapid development of peritonitis.

\section{G. Gösi ${ }^{1}$, F. Huoránszki ${ }^{2}$}

${ }^{1}$ Dept. of Surgery, Szt. Margit Hospital, Budapest, Hungary

${ }^{2}$ Dept. of Gastroenterology, Szt. Margit Hospital, Budapest, Hungary

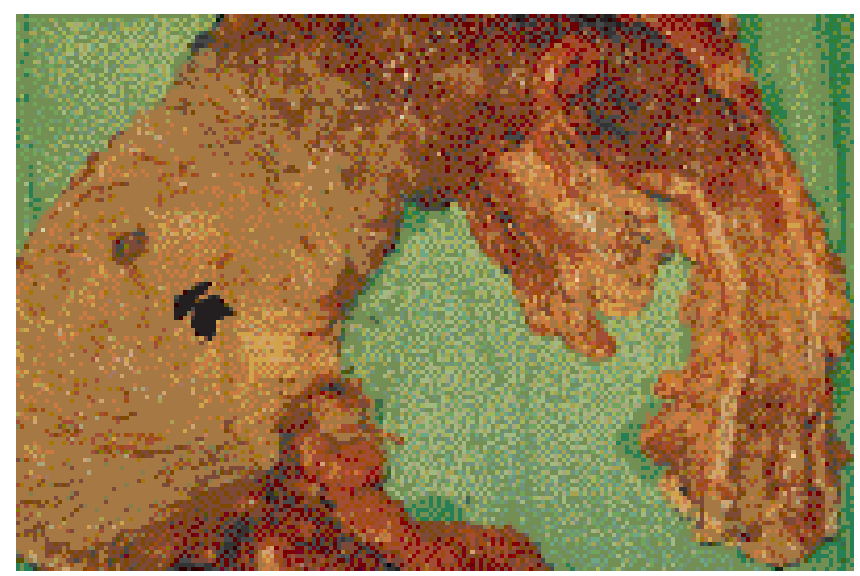

Figure 1 The specimen from the emergency total colectomy showed an acute ulcer on the unaffected short segment of the hepatic flexure (arrow)

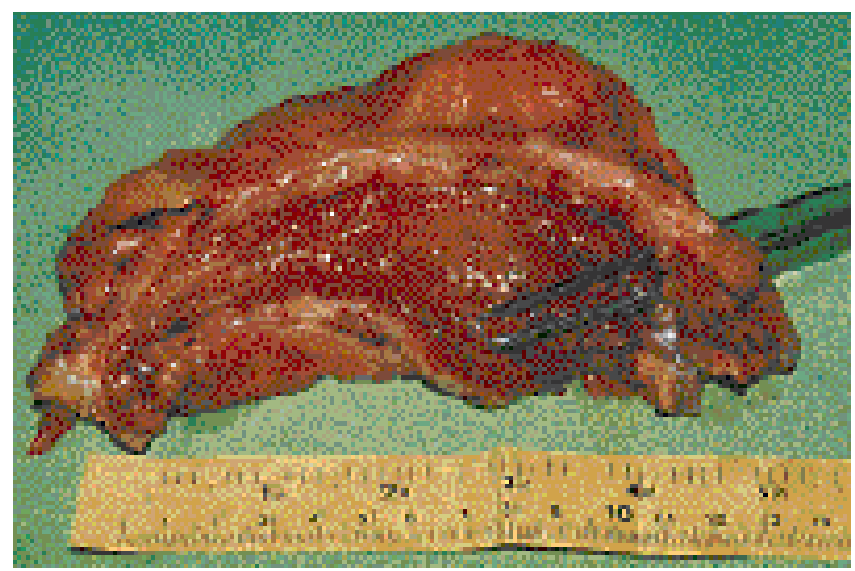

Figure 2 The specimen of the elective proctectomy proved that the strictured rectum with fistulas (forceps) would not have been suitable for restoration

\section{References}

${ }^{1}$ Höer J, Truong S, Virnich N, et al. Pneumatosis cystoides intestinalis: confirmation of diagnosis by endoscopic puncture. A review of pathogenesis, associated disease and therapy and a new theory of cyst formation. Endoscopy 1998; 30: $793-$ 799

${ }^{2}$ Pear BL. Pneumatosis intestinalis: a review. Radiology 1998; 207: 13-19

${ }^{3}$ Heng Y, Schuffler MD, Haggitt RC, Rohrmann CA. Pneumatosis intestinalis: a review. Am J Gastroenterol 1995; 90: $1747-1758$
${ }^{4}$ Boerner RM, Fried DB, Warshauer DM, Isaacs K. Pneumatosis intestinalis. Two case reports and a retrospective review of the literature from 1985 to 1995 . Dig Dis Sci 1996; 41: 2272-2285

Corresponding Author

G. Gösi, M.D.

Dept. of Surgery

Szt. Margit Hospital

Bécsi út 132

1032 Budapest

Hungary

Fax: +36-1-3682249

E-mail: gosiravasz@mail.matav.hu 